\title{
Natural Nano-Drug Delivery System in Coptidis Rhizoma Extract with Modified Berberine Hydrochloride Pharmacokinetics
}

\author{
Jing Zhaol,* \\ Qing Zhao',* \\ Jing-Ze Lu' \\ Dan $Y e^{\prime}$ \\ Sheng $\mathrm{Mu}^{\prime}$ \\ Xiao-Di Yang ${ }^{2}$ \\ Wei-Dong Zhang ${ }^{3,4}$ \\ Bing-Liang $\mathrm{Ma}^{\prime}$ \\ 'Department of Pharmacology, Shanghai \\ University of Traditional Chinese \\ Medicine, Shanghai, 201203, People's \\ Republic of China; ${ }^{2}$ Innovation Research \\ Institute of Traditional Chinese Medicine, \\ Shanghai University of Traditional \\ Chinese Medicine, Shanghai, 20I203, \\ People's Republic of China; ${ }^{3}$ Institute of \\ Interdisciplinary Integrative Medicine \\ Research, Shanghai University of \\ Traditional Chinese Medicine, Shanghai, \\ 20I203, People's Republic of China; \\ ${ }^{4}$ School of Pharmacy, Second Military \\ Medical University, Shanghai, 200433, \\ People's Republic of China \\ *These authors contributed equally to \\ this work
}

Correspondence: Wei-Dong Zhang;

Bing-Liang Ma

Email wdzhangy@hotmail.com;

bingliang.ma@hotmail.com
Purpose: This study aimed to evaluate the pharmaceutical and pharmacokinetic effects of the natural nanoparticles (Nnps) isolated from Coptidis Rhizoma extract on berberine hydrochloride (BBR) and systematically explore the related mechanisms.

Methods: Firstly, Nnps were isolated from Coptidis Rhizoma extract and then an Nnps-BBR complex was prepared. After qualitative and quantitative analysis in terms of size, Zeta potential, morphology, and composition of the Nnps and the Nnps-BBR complex, the effects of the Nnps on the crystallization of BBR were characterized. The effects of the Nnps on the solubility and dissolution of BBR were then evaluated. In addition, the effects of the Nnps on BBR in terms of cellular uptake, transmembrane transport, metabolic stability, and pharmacokinetics in mice were studied.

Results: The Nnps had an average size of $166.6 \pm 1.3 \mathrm{~nm}$ and Zeta potential of $-12.5 \pm 0.2 \mathrm{mV}$. The Nnps were formed by denaturation of co-existing plant proteins with molecular weight $<30$ $\mathrm{kDa}$. The Nnps adsorbed or dispersed BBR, thereby promoting BBR transformation from crystal to amorphous form and improving its solubility and dissolution. The Nnps carried and promoted BBR uptake by human colonic adenocarcinoma (Caco-2) cells via caveolae-mediated endocytosis, reducing P-gp-mediated efflux of BBR in mice gut sacs and Madin-Darby canine kidney cells stably expressing the transporter P-gp (MDCK-MDR1) cells. Moreover, the Nnps improved BBR metabolic stability in mouse intestinal S9, promoting BBR intestinal absorption in mice, as shown by increased peak BBR concentration $\left(\mathrm{C}_{\max }, 1182.3 \mathrm{vs} 310.2 \mathrm{ng} / \mathrm{mL}\right)$ and exposure level ( $\left.\mathrm{AUC}_{0-12} \mathrm{~h}, 2842.8 \mathrm{vs} 1447.0 \mathrm{ng} \cdot \mathrm{h} / \mathrm{mL}\right)$ in mouse portal vein. In addition, the Nnps increased BBR exposure level in mouse livers $(95,443.2 \mathrm{vs} 43,586.2 \mathrm{ng} \cdot \mathrm{h} / \mathrm{g}$ liver).

Conclusion: The proteinaceous nanoparticles isolated from Coptidis Rhizoma extract can form a natural nano-drug delivery system with BBR, thereby significantly improving the pharmacokinetics of oral BBR.

Keywords: natural nanoparticles, drug delivery system, pharmacokinetic synergy, berberine hydrochloride, herbal extract

\section{Introduction}

Herbal extracts are an important part of traditional medicines and used worldwide. ${ }^{1}$ In addition, herbal extracts are important sources of new drugs because they contain various compounds with novel structures and significant biological activities. ${ }^{2}$ Unfortunately, many compounds purified from herbal extracts are difficult to absorb after oral administration, which seriously limits their clinical applications. For example, the oral bioavailability of some representative active constituents of traditional Chinese medicines (TCMs), such as tanshinone IIA, ${ }^{3}$ berberine 


\section{Graphical Abstract}

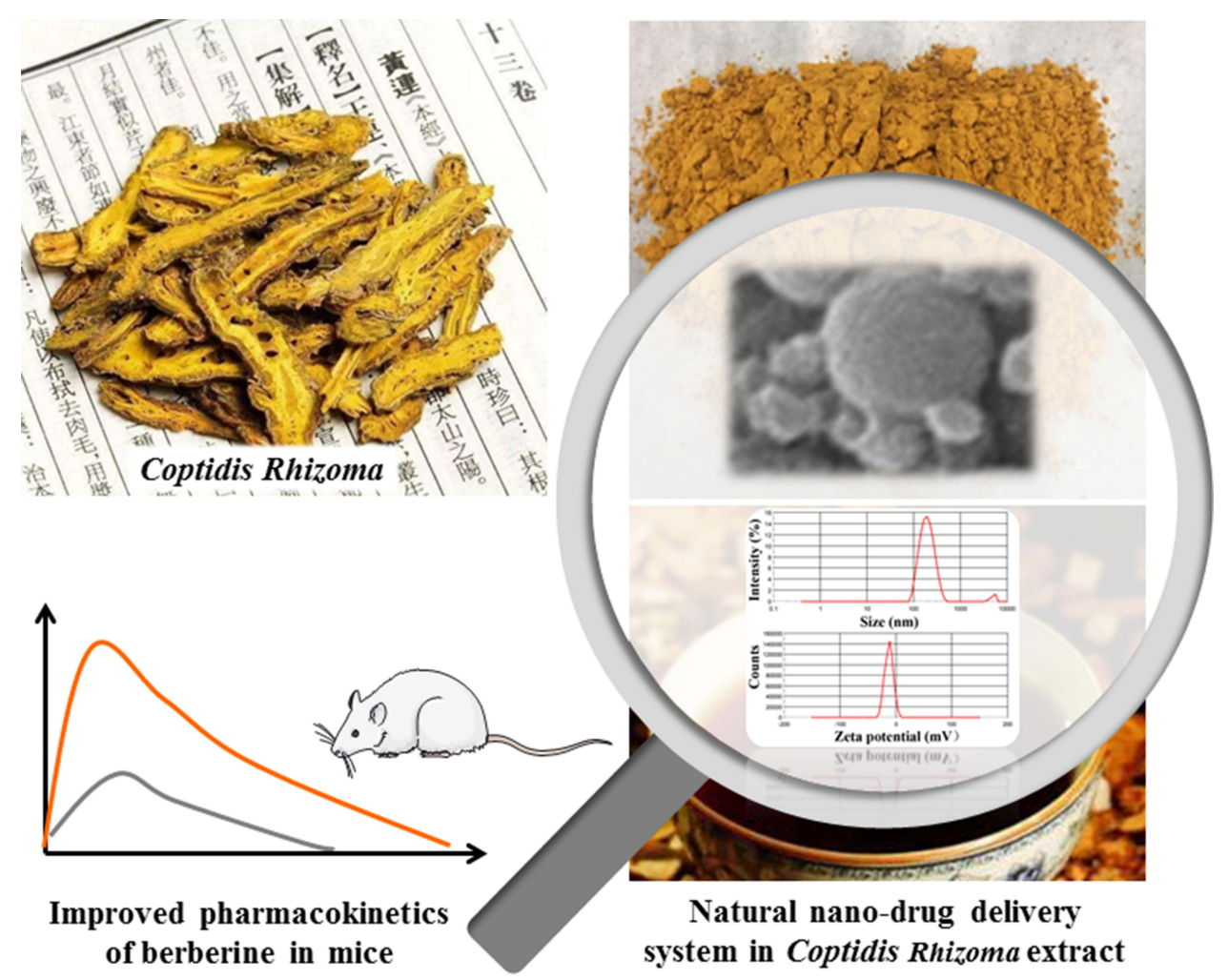

hydrochloride (BBR), ${ }^{4}$ astragaloside $\mathrm{IV}^{5}{ }^{5}$ baicalin, ${ }^{6}$ curcumin, ${ }^{7}$ ginsenoside $\mathrm{Rb}_{1}, \mathrm{Rb}_{2}, \mathrm{Rb}_{3},{ }^{8}$ glycyrrhizin, ${ }^{9}$ and platycodinD ${ }^{10}$ are all less than $5 \%$. However, the absorption of these compounds is usually better after oral administration of the corresponding herbal extracts. ${ }^{11}$ In the case of tanshinone IIA, the exposure level of tanshinone IIA in rats receiving oral Salviae Miltiorrhizae Radix et Rhizoma extract was more than 19 times higher than that in rats receiving oral tanshinone IIA. ${ }^{3}$

Pharmacokinetic synergy occurs in herbal extracts. ${ }^{11}$ For example, some secondary metabolites contribute to the synergy. ${ }^{11}$ More importantly, there are some primary metabolites in herbal extracts, including proteins and polysaccharides, which are usually high in content. The role of primary metabolites in herbal extracts has attracted increasing attention. ${ }^{11}$ For example, some polysaccharides have prebiotic-like effects, which can increase the hydrolysis of saponins by promoting the proliferation of intestinal bacteria and improving their metabolic capacity, thus producing glycoside ligands that are more easily absorbed. ${ }^{12,13}$ More importantly, proteins and polysaccharides may directly modify the existing forms and intestinal absorption of active constituents. In Zhuang's study, natural nanoparticles (Nnps) were observed in the water extracts of 60 types of TCMs and 24 types of TCM formulas. ${ }^{14}$ Nnps are usually composed of proteins, polysaccharides, and lipids. ${ }^{15-19}$ Importantly, Nnps can adsorb active constituents, ${ }^{17,20-22}$ carry them for absorption, ${ }^{20,23,24}$ and distribute them to target tissues. ${ }^{17}$ These results suggest that Nnps may affect the pharmaceutical and pharmacokinetic properties of the active constituents in herbal extracts. However, no systematic studies have been conducted to date.

Coptidis Rhizoma is the dried rhizome of Coptis chinensis Franch, Coptis deltoidei C. Y. Chen et Hsiao, or Coptis teeta Wall. It is one of the most commonly used TCMs. BBR has a wide range of pharmacological effects and is the main active constituent of Coptidis Rhizoma. ${ }^{25}$ However, after oral administration, owing to poor water solubility, approximately $56 \%$ of BBR is excreted directly with feces. ${ }^{4,26,27}$ In addition, BBR is excreted by intestinal efflux transporters such as p-glycoprotein (P-gp), and metabolized by intestinal drug-metabolizing enzymes, resulting in an intestinal elimination of $43.5 \%$ of the oral 
dose. ${ }^{4,26,27}$ After entering the liver through the portal vein, it is further metabolized by the liver and excreted via bile. $^{4,26,27}$ In short, owing to poor solubility and significant first-pass elimination, the bioavailability of oral BBR is as low as $0.36 \%{ }^{4,26,27}$ However, it was found that the exposure level of BBR in mice receiving oral Coptidis Rhizoma extract could be 15 times higher than that in mice receiving oral BBR. ${ }^{20,28}$ Moreover, Nnps are spontaneously formed by proteins in Coptidis Rhizoma extract, and these Nnps can adsorb and carry BBR to be absorbed by intestinal epithelial cells. ${ }^{20}$ However, the effects and mechanisms of these Nnps on the pharmaceutical and pharmacokinetic properties of BBR remain to be elucidated.

Therefore, this study aimed to evaluate the pharmaceutical and pharmacokinetic effects of the Nnps isolated from Coptidis Rhizoma extract on BBR and systematically explore the related mechanisms. In view of the widespread existence of Nnps in herbal extracts, this study is expected to promote more research on the interactions between Nnps and small-molecule constituents in herbal extracts.

\section{Materials and Methods Materials}

The dried Coptidis Rhizoma was purchased from Shanghai Kang Qiao Herbal Pieces Co., Ltd. (Shanghai, China). The herbal pieces were collected and produced in Sichuan province, China. According to the Pharmacopeia of the People's Republic of China (2015 edition), the herbal pieces were identified as the root of $C$. chinensis. A voucher specimen (No.180305) was deposited at the Department of Pharmacology, School of Pharmacy, Shanghai University of Traditional Chinese Medicine, China. Further study approvals were not required according to regional guidelines.

The purity of all the reference compounds used in this study was more than $98 \%$. BBR, coptisine, epiberberine, palmatine, demethyleneberberine, carbamazepine, verapamil hydrochloride, filters $(0.22 \mu \mathrm{m})$, and dialysis membranes (3500 D) were purchased from Shanghai Yuanye Biological Co., Ltd. (Shanghai, China). Amiloride, cytochalasin D, and indomethacin were purchased from Dalian Meilun Biotechnology Co., Ltd. (Dalian, China). Chlorpromazine, dimethyl sulfoxide, and acetonitrile were purchased from Merck \& Co., Inc. (New Jersey, USA). The BCA (diquinolinic acid) protein test kit was obtained from Shanghai Biyuntian Biotechnology Co., Ltd. (Shanghai, China). The pooled CD-1 mouse intestine $\mathrm{S} 9$ fraction was obtained from SEKISUI Medical Co. Ltd (Tokyo, Japan). Formic acid, ammonium formate, fetal bovine serum, and Dulbecco's modified Eagle's medium (DMEM) were the product of Thermo Fisher Scientific (Massachusetts, USA). Trypsinase and penicillin-streptomycin solutions were obtained from Biosharp (Hefei, China). The pure water used in the current study was prepared using a Millipore Milli-Q system (Massachusetts, USA).

\section{Cell Culture}

Human colonic adenocarcinoma cells (Caco-2) and Madin-Darby canine kidney cells stably expressing the transporter P-gp (MDCK-MDR1) were provided and authenticated by Sandia Pharmaceutical Technology (Shanghai) Co., Ltd. (Shanghai, China). The cells were cultured at $37^{\circ} \mathrm{C}$ in DMEM supplemented with $10 \%$ FBS, penicillin-streptomycin solution, and HEPES (15 $\mathrm{mM}$ ) in a humidified atmosphere of $5 \% \mathrm{CO}_{2}$. Hank's balanced salt solution (HBSS) [consisting of (mM) 135 $\mathrm{NaCl}, 1.2 \mathrm{MgCl}_{2}, 0.81 \mathrm{MgSO}_{4}, 27.8$ glucose, $2.5 \mathrm{CaCl}_{2}$, and 25 HEPES, pH 7.2)] was used to replace the culture medium in the incubation experiments. When dimethyl sulfoxide (DMSO) was used, its final concentration in HBSS was restricted to less than $1 \%$.

\section{Animals}

ICR mice (Grade II, male and female, $24 \pm 2 \mathrm{~g}$ body weight) were purchased from Shanghai Slac Laboratory Animal Co., Ltd. (Shanghai, China). The mice were housed in an air-conditioned room at $22-24^{\circ} \mathrm{C}$ with a dark/light cycle of $12 / 12 \mathrm{~h}$. Before the experiment, the mice were fasted for approximately $12 \mathrm{~h}$, but were allowed to drink water freely. All animal experimental protocols were approved by the Institutional Animal Care and Use Committee of Shanghai University of Traditional Chinese Medicine (PZSHUTCM19011105). All experiments were performed in accordance with the Guidelines for Care and Use of Laboratory Animals of Shanghai University of Traditional Chinese Medicine.

\section{Liquid Chromatography-Mass Spectrometry (LC-MS) Assay}

The LC-MS system was composed of a Shimadzu HPLC (LC-20AD) system (Kyoto, Japan) and a Thermo Scientific LCQ fleet mass spectrometer (Massachusetts, USA) equipped with an electrospray ionization (ESI) source. An 
Eclipse XDB-C18 $(4.6 \times 150 \mathrm{~mm}, 5 \mu \mathrm{m})$ maintained at room temperature was used for chromatographic separation of the analytes. Water containing formic acid $(0.0625 \%)$ and ammonium formate $(4 \mathrm{mM})$ was used as mobile phase $\mathrm{A}$, and methanol was used as mobile phase $\mathrm{B}$. The following elution gradient was used at a flow rate of $0.3 \mathrm{~mL} / \mathrm{min}: 0-7$ min, $20 \%$ to $30 \%$ B; $7.01-10 \mathrm{~min}, 20-20 \%$ B. Data acquisition was performed in the selected ion monitoring mode. The protonated $[\mathrm{M}+\mathrm{H}]^{+}$ions of berberine and epiberberine $(\mathrm{m} / \mathrm{z} 336.2$, with different retention times), coptisine $(\mathrm{m} / \mathrm{z}$ 320.2), palmatine ( $\mathrm{m} / \mathrm{z} 352.1)$, and carbamazepine (internal standard, $\mathrm{m} / \mathrm{z}$ 237.0) were generated. The linear dynamic ranges for berberine, epiberberine, coptisine, and palmatine ranged from 0.156 to $10 \mu \mathrm{g} / \mathrm{mL}$. The method was validated in terms of accuracy, precision, recovery, repeatability, and stability (data not shown), and it met the requirements of quantitative analysis of the alkaloids in samples with relatively high concentrations.

\section{Liquid Chromatography Tandem Mass Spectrometry (LC-MS/MS) Assay}

The biological samples in this study were precipitated in three volumes of acetonitrile. After centrifugation at $16,000 \mathrm{rpm}$ for $10 \mathrm{~min}$ at $4^{\circ} \mathrm{C}$, an equal volume of water was added and mixed with the supernatant. Then, $10 \mu \mathrm{L}$ of each sample was injected for analysis using an LC-MS/MS system, which was composed of an HPLC (LC-20AD) from Shimadzu and a Thermo Scientific TSQ Quantum Ultra mass spectrometer (Massachusetts, USA). A C18 analytical column (Hypersil Gold, $5 \mu \mathrm{m}, 100 \times 2.1 \mathrm{~mm}$ ) was used for chromatographic separation of the analytes. The mobile phase was composed of solvent A (formic acid $[0.08 \%, \mathrm{v} / \mathrm{v}]$ and ammonium acetate $[2 \mathrm{mM}]$ in water) and solvent $\mathrm{B}$ (acetonitrile). The following elution gradient was used at a flow rate of $0.3 \mathrm{~mL} / \mathrm{min}: 0-7$ $\min , 15 \%$ to $68 \% \mathrm{~B} ; 7.01-10 \mathrm{~min}, 15-15 \% \mathrm{~B}$. The positive ion mode was used for the ESI source, and data acquisition was performed in the multiple reaction monitoring mode: $\mathrm{m} / \mathrm{z} \quad 336.2 \rightarrow 322.3, \quad \mathrm{~m} / \mathrm{z}$ $324.3 \rightarrow 308.0, \mathrm{~m} / z \quad 237.0 \rightarrow 194.3$ for berberine, demethyleneberberine, and carbamazepine (internal standard), respectively. The linear range of berberine was 1.95$1000 \mathrm{ng} / \mathrm{mL}$. The validated method was used in our published studies, and it met the requirements of quantitative analysis of the alkaloids in biological samples having relatively low concentrations. ${ }^{29,30}$

\section{Preparation and Quality Control of Coptidis Rhizoma Extract}

Briefly, the herbal pieces of Coptidis Rhizoma were extracted twice with 10 times the volume of boiling water ( $1.5 \mathrm{~h}$ for the first and $1 \mathrm{~h}$ for the second extraction). The obtained aqueous extract was then filtered through eight layers of gauze and vacuum-dried at $60^{\circ} \mathrm{C}$.

The contents of berberine, epiberberine, coptisine, and palmatine in Rhizoma Coptidis extract were detected for quality control. Briefly, the powder of the extract was dissolved in methanol $(1 \mathrm{mg} / \mathrm{mL})$ and ultrasonicated for $60 \mathrm{~min}$. After centrifugation at $16,000 \mathrm{rpm}$ for $10 \mathrm{~min}$, the obtained supernatant was injected into the LC-MS system for quantitative analysis.

\section{Preparation and Characterization of Nnps and Nnps-BBR Complex}

The powder of Coptidis Rhizoma extract was dissolved in water. After ultrasonic treatment for $1 \mathrm{~h}$, the solution was centrifuged at $3000 \mathrm{rpm}$ for $10 \mathrm{~min}$. The obtained supernatant was filtered through a $0.22-\mu \mathrm{m}$ filter. The filtered solution was then dialyzed in a dialysis bag $(3500 \mathrm{D})$ against water for five consecutive days. Nnps were obtained by freeze-drying the residues in the dialysis bag. In addition, the Nnps and BBR were dissolved in water at a weight ratio of $1: 1$. The solution was then boiled for $1 \mathrm{~h}$ and then lyophilized to obtain the Nnps-BBR complex powder.

The particle size and Zeta potential in the aqueous solution of the Nnps or the Nnps-BBR complex were determined using a Malvern Zetasizer Nano analyzer (Worcestershire, UK). The powder of the Nnps or the Nnps-BBR complex was sprayed with gold, dried in vacuum, and then observed under an FEI Quanta 250 scanning electron microscope (SEM) (Oregon, USA) operating at $10 \mathrm{kV}$. A Leica SP8 laser confocal fluorescence microscope (LCFM) (Wetzlar, Germany) was used to observe the morphology of the powder of the Nnps or the Nnps-BBR complex. The protein content in the Nnps was determined using a BCA kit. The content of polysaccharide in the Nnps was determined by phenol sulfuric acid method using glucose as a reference standard. The content of alkaloids in the Nnps or the Nnps-BBR complex was determined using the LC-MS method.

\section{Isolation and Identification of Nnps-Forming Protein}

To obtain the undenatured Nnps-forming proteins, a new Coptidis Rhizoma extract was prepared according to the 
method described in section "Preparation and quality control of Coptidis Rhizoma extract", but the extraction temperature was maintained at $50^{\circ} \mathrm{C}$. The proteins in the extract were obtained by dialysis according to the method described in section "Preparation and characterization of Nnps and Nnps-BBR complex". After dissolving, the purity and molecular weight of the proteins were determined by standard gel electrophoresis (SDS-PAGE) in 4\% concentrating gel and $10 \%$ separating gel and stained with silver, with a protein gel electrophoresis device (Bio-Rad, USA). In addition, after the protein solution was boiled for $1 \mathrm{~h}$, the particle size and Zeta potential of the formed particles were measured using the Malvern Zetasizer Nano analyzer.

\section{Effect of Nnps on the Crystal Form of BBR}

The morphologies of BBR, the Nnps, and the Nnps-BBR complex were observed by SEM. Differential scanning calorimetry (DSC) and powder X-ray diffraction (PXRD) were also performed to verify the effect of the Nnps on the crystal form of BBR. For the DSC analysis, approximately $1.5 \mathrm{mg}$ of powder samples were placed in open aluminum crucibles and heated from $20^{\circ} \mathrm{C}$ to $320^{\circ} \mathrm{C}$ at $10^{\circ} \mathrm{C} / \mathrm{min}$ using a TA DSC Q2000 differential scanning calorimeter (Delaware, USA). For the PXRD analysis, a Bruker D2 phaser (Rheinstetten, Germany) system was used. The running conditions were maintained at a voltage of $30.0 \mathrm{kV}$ and a current of $10.0 \mathrm{~mA}$. The increment was $0.02^{\circ}$, the scan range was from $3^{\circ}$ to $40^{\circ}$, and the scan speed was $0.1 \mathrm{~s} / \mathrm{step}$.

\section{Effect of Nnps on the Solubility of BBR}

Supersaturated aqueous solutions of BBR, the Nnps, and the Nnps-BBR complex were prepared. The concentration of BBR in each group was equal, that is, $10 \mathrm{mg} / \mathrm{mL}$. After ultrasonic treatment for $1 \mathrm{~h}$, the solutions were centrifuged at $16,000 \mathrm{rpm}$ for $10 \mathrm{~min}$ to obtain the supernatant. The concentration of BBR in the supernatant was determined using the LC-MS method.

\section{Effect of Nnps on the Dissolution of BBR}

The experiments were performed using a Tianda RC-MD dissolution tester (Tianjin, China) based on a rotating basket method, where the speed of the basket was maintained at $50 \mathrm{rpm}$ and the temperature of the dissolution medium was maintained at $37 \pm 0.5^{\circ} \mathrm{C}$. The samples (BBR, the Nnps, the Nnps-BBR complex) containing $10 \mathrm{mg}$ of BBR were enclosed in blank capsules and placed in the baskets. The baskets were then placed into the dissolution vessel containing $900 \mathrm{~mL}$ of hydrochloric acid buffer (2.0 g sodium chloride, $\mathrm{pH}$ 1.2), mimicking the gastric fluid or $900 \mathrm{~mL}$ of phosphate buffer $(0.2 \mathrm{M}$ sodium phosphate, $\mathrm{pH}$ 6.8), mimicking the intestinal juices. For the experiments in hydrochloric acid buffer, samples were collected at $5,10,15,20,30,45,60$, and $90 \mathrm{~min}$. For experiments in phosphate buffer, samples were collected at $2.5,5,15$, and $30 \mathrm{~min}$, and 1, 2, 3, 4, and $6 \mathrm{~h}$, respectively. The samples were filtered through a $0.22-\mu \mathrm{m}$ filter. After centrifugation $(16,000 \mathrm{rpm}, 10 \mathrm{~min})$, the concentration of BBR in each sample was determined using the LC-MS method.

\section{Endocytosis of Nnps}

Caco-2 cells were cultured until they reached $80-90 \%$ confluence. The culture medium was changed $2 \mathrm{~h}$ prior to the experiment. After washing with warmed HBSS, the cells were incubated with BBR $(10 \mu \mathrm{g} / \mathrm{mL})$, the Nnps (containing $10 \mu \mathrm{g} / \mathrm{mL} \mathrm{BBR}$ ), or the Nnps plus various endocytosis inhibitors $(2.5 \mathrm{~mm}$ amiloride, a macropinocytosis inhibitor ${ }^{31} 100 \mu \mathrm{g} / \mathrm{mL}$ indomethacin, an inhibitor of caveolae-mediated endocytosis; ${ }^{32} 10 \mu \mathrm{g} / \mathrm{mL}$ chlorpromazine, an inhibitor of clathrin-mediated endocytosis; $^{32} 5 \mu \mathrm{M}$ cytochalasin $\mathrm{D}$, a phagocytosis inhibitor $^{31}$ ). After incubation for $4 \mathrm{~h}$, the culture medium was removed, and the cells were washed with HBSS. After trypsin digestion, the cells were collected by centrifugation at $1000 \mathrm{rpm}$ for $2 \mathrm{~min}$. The cells were then washed twice with HBSS. Then, the cells were resuspended in chilled water and were broken by repeated freezing and thawing. The concentration of BBR was determined using the LCMS/MS method, and the protein concentration of each sample was determined using a BCA kit. The concentration of BBR in each group was normalized to the protein content.

\section{Effect of Nnps on the Transportation of BBR in Gut Sacs}

A segment of the ileum approximately $12 \mathrm{~cm}$ long was washed with chilled Krebs-Ringer buffer $(118 \mathrm{mM} \mathrm{NaCl}$, $25 \mathrm{mM} \mathrm{NaHCO}_{3}, 1.2 \mathrm{mM} \mathrm{MgSO}_{4}, 2.5 \mathrm{mM} \mathrm{CaCl}_{2}, 11 \mathrm{mM}$ glucose, $1.2 \mathrm{mM} \mathrm{KH}{ }_{2} \mathrm{PO}_{4}$, and $4.7 \mathrm{mM} \mathrm{KCl}, \mathrm{pH} 6.8$ ), and then ligated at one end. To study the transportation of BBR from the mucosal side to the serosal side, the inner mucosal side of the gut sac was filled with $1 \mathrm{~mL}$ of Krebs-Ringer buffer containing BBR $(10 \mathrm{mg} / \mathrm{mL})$, the Nnps, or the Nnps- 
BBR complex, which has the corresponding concentration of BBR. To study the transportation of BBR from the serosal side to the mucosal side, the gut sac was everted and filled on the inner serosal side with $1 \mathrm{~mL}$ Krebs-Ringer buffer containing BBR $(200 \mu \mathrm{g} / \mathrm{mL}$ BBR) or the Nnps, or the NnpsBBR complex, which has the corresponding concentration of BBR. The other end of the ileum was ligated tightly. The sac was incubated at $37^{\circ} \mathrm{C}$ in a Magnus bath containing $20 \mathrm{~mL}$ of blank Krebs-Ringer buffer. Aliquots of buffer $(100 \mu \mathrm{L})$ were sampled from the Magnus bath after incubation for 15, 30, 45 , or $60 \mathrm{~min}$. An equal volume of blank Krebs-Ringer buffer was immediately added. The concentrations of BBR in the obtained samples were determined and normalized using the lengths of the sacs that were measured after incubation.

\section{Effect of Nnps on the Transportation of BBR Across MDCK-MDRI Cell Monolayer}

MDCK-MDR1 cells were seeded on a Merck Transwell polycarbonate membrane (New Jersey, USA) at a density of $2 \times 10^{5}$ cells $/ \mathrm{mL}$. The cells were cultured until tight junctions were formed (trans-epithelial electrical resistance value $>500 \Omega \cdot \mathrm{cm}^{2}$ ). Before the experiment, the medium on both sides of the chamber was replaced with a warmed HBSS solution. The cells were then equilibrated for $20 \mathrm{~min}$ in an incubator. For the transportation test from the apical (AP) to the basolateral (BL) sides, $0.2 \mathrm{~mL}$ of HBSS solution containing BBR or the Nnps (both have $10 \mu \mathrm{g} / \mathrm{mL}$ the final concentration of BBR) was added to the AP side, and $0.7 \mathrm{~mL}$ blank HBSS solution was added to the BL side. For the transportation test from the BL to AP side, $0.2 \mathrm{~mL}$ of blank HBSS solution was added to the AP side and $0.7 \mathrm{~mL}$ of HBSS solution containing BBR or the Nnps (both have $10 \mu \mathrm{g} / \mathrm{mL}$ the final concentration of BBR) was added to the $\mathrm{BL}$ side. After incubation for 2 or $4 \mathrm{~h}$, the solutions on both sides were aspirated, and the concentration of BBR was determined using the LC-MS/MS method.

\section{Effect of Nnps on the Metabolism Stability of BBR in Intestinal S9}

The test materials (BBR and the Nnps, both with $10 \mu \mathrm{g} / \mathrm{mL}$ final concentration of BBR) were mixed with the intestinal $\mathrm{S} 9(2 \mathrm{mg} / \mathrm{mL})$ in $100 \mu \mathrm{L}$ Tris- $\mathrm{HCl}(50 \mathrm{mM}, \mathrm{pH} 7.4)$ buffer solution and then preincubated at $37^{\circ} \mathrm{C}$ for $5 \mathrm{~min}$. Then, reduced nicotinamide adenine dinucleotide phosphate (NADPH, $1 \mathrm{mg} / \mathrm{mL}$ ) was added to start the reaction. After incubation for 0.5 or $1 \mathrm{~h}$, the incubation was terminated with the same amount of chilled methanol, which contained the internal standard carbamazepine. After centrifugation at $16,000 \mathrm{rpm}$ for $6 \mathrm{~min}$, the obtained supernatant was diluted to determine the concentration of BBR and demethylberberine using the LC-MS/MS method. The metabolic stability of BBR was characterized by the concentration of residual $\mathrm{BBR}$ and the produced demethylberberine.

\section{Effect of Nnps on the Pharmacokinetics of Oral BBR in Mice}

Mice were randomly divided into three groups, which were orally administered the water solution of BBR, the Nnps-BBR complex, or Coptidis Rhizoma extract. BBR dosage in each group was $200 \mathrm{mg} / \mathrm{kg}$. The dose of BBR was consistent with its dosage in reported studies in mice, ie, $0.1-0.3 \mathrm{~g} / \mathrm{kg}^{27}$ Six mice in each group were anesthetized using diethyl ether at $0.5,1,2,4,8$, or $12 \mathrm{~h}$ after administration. Blood samples were collected from the portal vein or the posterior orbital venous plexus to heparin-containing tubes. Plasma samples were obtained by centrifugation of blood samples at $3000 \mathrm{rpm}$ for $10 \mathrm{~min}$ at $4{ }^{\circ} \mathrm{C}$. The livers of the mice were collected and homogenized in 10 volumes of water. At the end of the experiment, the mice were euthanized by cervical dislocation. The plasma and liver homogenate samples were stored at $-80^{\circ} \mathrm{C}$. The concentration of BBR in each sample was determined using the LC-MS/MS method.

\section{Data Analysis}

The permeability of BBR in the MDCK-MDR1 experiment was calculated using the equation:

$$
P_{\text {app }}=\Delta Q /\left(\Delta t \times A \times C_{0}\right)
$$

where $\Delta \mathrm{Q}$ is the amount of drug transported within $\Delta \mathrm{t}$ time, $\mathrm{A}$ is the surface area $\left(0.33 \mathrm{~cm}^{2}\right.$ in this experiment), and $\mathrm{C}_{0}$ is the initial concentration of $\mathrm{BBR}$ on the donor side. The unit of $P_{\text {app }}$ was $\mathrm{cm} / \mathrm{s}$.

The efflux rate (ER) of BBR in the MDCK-MDR1 experiment was calculated using the following equation:

$$
E R=P_{a p p(B L-A P)} / P_{a p p}(A P-B L)
$$

A non-compartmental analysis using the WinNonlin ${ }^{\circledR}$ software (Pharsight, CA, USA) was performed to obtain the pharmacokinetic parameters. It should be noted that the pharmacokinetic parameters were calculated based on the average drug concentration at each time point because the mice were not continuously sampled. 
The results were expressed as mean $\pm \mathrm{SD}$, and statistical significance was determined with one-way or two-way analysis of variance (ANOVA) for multiple comparisons with the minimum level of significance $(p<0.05)$.

\section{Results}

\section{Characterization of the Nnps}

The residues in the dialysis bag were obtained via dialysis of Coptidis Rhizoma extract. The content of the residues in the Coptidis Rhizoma extract was $6.2 \%$ (Figure 1A). The residues were mainly composed of proteins $(>90 \%)$. In addition, the content of polysaccharide in the residues was above $30 \%$. It should be noted that the presence of glucose could lead to overestimation of protein quantification. ${ }^{33}$ This may be one of the reasons why the total content of protein and polysaccharides exceeded $100 \%$. Furthermore, the residues contained approximately $8 \%$ BBR, which was difficult to remove even after 5 days of dialysis. The freeze-dried powder of the residues dispersed into $166.6 \pm 1.3 \mathrm{~nm}$ nanoparticles (ie, Nnps) in water, with a Zeta potential of approximately $-12.5 \pm 0.2$ $\mathrm{mV}$ (Figure 1B). Owing to insolubility after denaturation, it was impossible to directly determine the purity and molecular weight of the protein forming the Nnps by gel electrophoresis. From the Coptidis Rhizoma extract obtained by decocting the herbal pieces at temperatures below $50^{\circ} \mathrm{C}$, a purified and soluble protein with a molecular weight $<30 \mathrm{kD}$ was obtained (Figure 1C). After decocting the protein in boiling water for $1 \mathrm{~h}$, nanoparticles with a size of $176.1 \pm 10.1 \mathrm{~nm}$ and a Zeta potential of $-19.3 \pm 0.6 \mathrm{mV}$ were formed, indicating that the Nnps were formed by the denaturation and self-assembly of the protein. Under SEM, spherical particles were observed in the Nnps powder, and smaller particles were distributed around them (Figure 1D). The drug mass formed by small, green fluorescent particles was observed under LCFM (Figure 1E), and dispersed green fluorescent particles were observed in the aqueous solution (Figure 1F). Green fluorescence originates from BBR, according to literature. ${ }^{34}$ In short, the Nnps isolated from Coptidis Rhizoma extract were mainly formed by denaturation of a protein and can firmly adsorb BBR.

\section{The Nnps Changed the Crystal Form of BBR} Under SEM (Figure 2A) and LCFM (Figure 2Ca), long columnar crystals were observed in the BBR powder, but not in the Nnps-BBR complex powder (Figures 2B and Cc).
Under LCFM, bamboo leaf-like crystals were observed in the BBR solution (Figure 2Cb), but green fluorescent particles were found in the Nnps-BBR complex solution (Figure 2Cd). DLS analysis showed that the Nnps-BBR complex was dispersed into nanoparticles with a size of $151.3 \pm 1.2 \mathrm{~nm}$ and a Zeta potential of $-11.6 \pm 1.2 \mathrm{mV}$ in water. DSC analysis showed that the melting point of BBR was approximately $194.97^{\circ} \mathrm{C}$, which is consistent with that in literature, ${ }^{35}$ whereas the melting point of the Nnps-BBR complex decreased to $175.22^{\circ} \mathrm{C}$ (Figure 2D). BBR had many characteristic sharp interference peaks in its PXRD pattern, but reduced or disappeared in the PXRD pattern of the Nnps-BBR complex (Figure 2E). The above results indicated that the Nnps acted as nanocarriers to adsorb or disperse BBR, thereby promoting its transformation from crystal to amorphous form.

\section{The Nnps Improved the Solubility and Dissolution Rate of BBR}

When a drug is in an amorphous form, it often has a better solubility and dissolution than that in the crystal form. ${ }^{36}$ As shown in Figure 3A, the solubility of BBR in the NnpsBBR complex was significantly higher than that of pure BBR. The dissolution rates of BBR in artificial gastric juice (Figure 3B) and intestinal juice (Figure 3C) were only $7.5 \%$ and $1.8 \%$ at $15 \mathrm{~min}$, and $35.3 \%$ and $60.9 \%$ at the end point $(1.5 \%$ or $6 \mathrm{~h})$, respectively. However, the dissolution rate of BBR in the Nnps increased to $50.8 \%$ and $31.5 \%$ at $15 \mathrm{~min}$ and $69.1 \%$ and $85.4 \%$ at the end point, respectively. In addition, the dissolution rate of BBR in the Nnps-BBR complex increased to $54.55 \%$ and $22.55 \%$ at $15 \mathrm{~min}$, and $60.0 \%$ and $81.37 \%$ at the end of dissolution, respectively.

\section{The Nnps Improved the Intestinal Absorption of BBR}

Nanoparticles are mainly absorbed via endocytosis. ${ }^{37}$ Indomethacin significantly reduced the uptake of BBR in Caco-2 cells (Figure 4A, $p<0.01$ ), indicating that BBR carried by the Nnps was absorbed mainly by caveolaemediated endocytosis. Based on the in vitro absorption experiment using mouse gut sacs, it was found that the intestinal absorption of BBR in the Nnps and the NnpsBBR complex was significantly better than that of pure BBR (Figure 4B, $p<0.01$ ), indicating that the Nnps could adsorb BBR and act as a nanocarrier to promote the absorption of BBR. Furthermore, the Nnps significantly reduced 


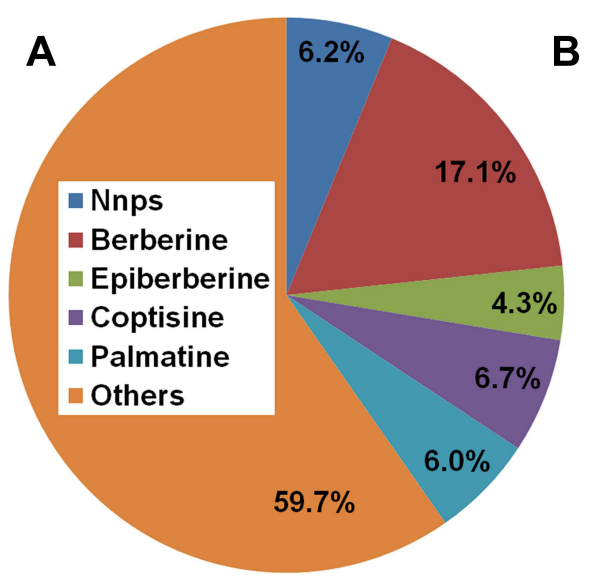

D

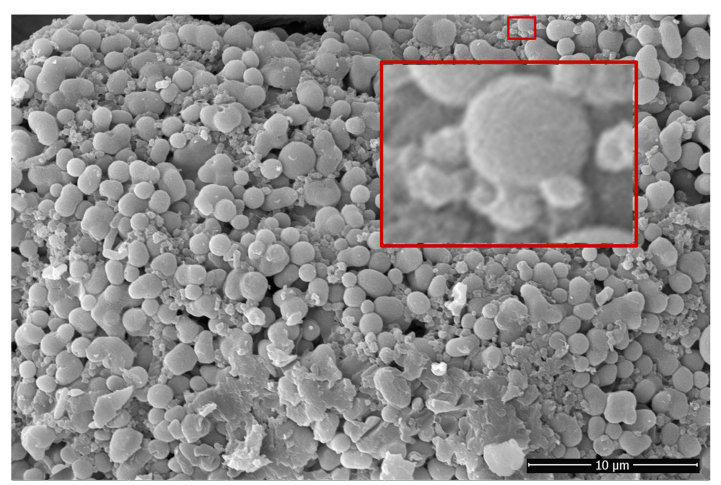

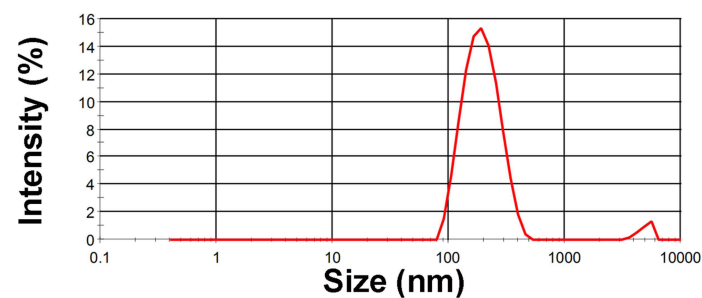

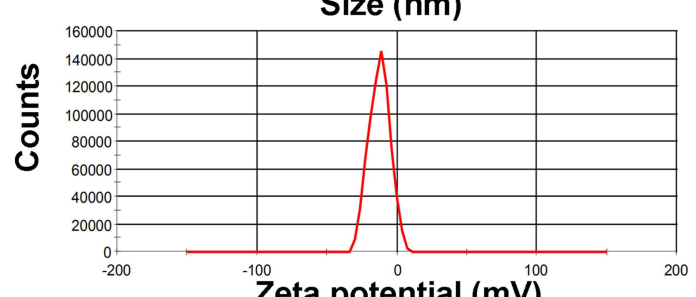

E

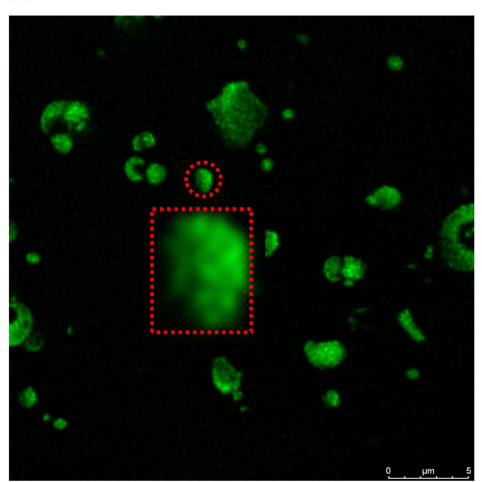

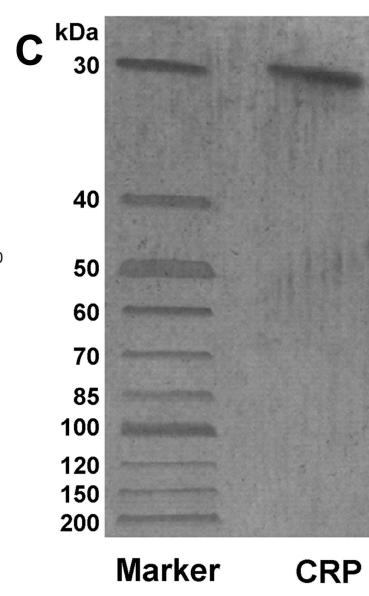

$\mathbf{F}$

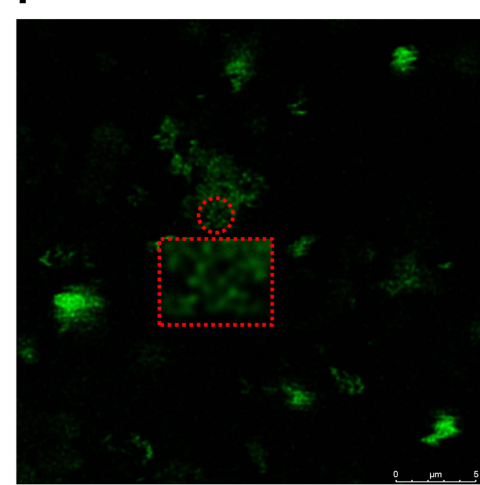

Figure I Characterization of the natural nanoparticles (Nnps) isolated from Coptidis Rhizoma extract; (A) Content of Nnps in Coptidis Rhizoma extract; (B) Size and Zeta potential of Nnps; (C) Purity and molecular weight of the protein molecules (CRP, Coptidis Rhizoma protein) forming Nnps; (D) Scanning electron microscope observation of Nnps powder (10,000 x); (E) Observation of Nnps powder by laser confocal fluorescence microscopy $(6000 \times)$; (F) Observation of the water solution of Nnps by laser confocal fluorescence microscopy $(6000 \times)$. In Figure ID, the large red rectangle showed an enlarged image of the Nnps contained in the small red rectangle. In Figure IE and F, the red dotted rectangle showed an enlarged image of the Nnps contained in the small red dotted circle, respectively.

BBR efflux from the gut sacs (Figure 4C, $p<0.01$ ). Verapamil, a typical P-gp inhibitor, ${ }^{38}$ significantly reduced the efflux of BBR in both the BBR and the Nnps groups (Figure 4C). However, the effect on the Nnps group was less than that on the BBR group, suggesting that the Nnps could reduce the P-gp-mediated efflux of BBR (Figure 4C). The results of in vitro experiments based on MDCK-MDR1 cells (Table 1) showed that the $P_{a p p}$ of BBR was lower than $10^{-6} \mathrm{~cm} / \mathrm{s}$, indicating that its permeability was poor. The ERs of BBR were as high as 25.8 at $2 \mathrm{~h}$ and 39.5 at $4 \mathrm{~h}$, respectively. According to the recommendations of the International Transporter Consortium, a compound is considered to be a potential P-gp substrate if the ER is $\geq 2$. $^{39}$ The ERs of BBR were far greater than the critical value of 2 , indicating that $\mathrm{P}$-gp-mediated efflux significantly restricted BBR uptake. In contrast, the Nnps significantly reduced the $P_{a p p}$ from BL to AP as well as the ERs (all $p<0.01$ ), confirming that the Nnps inhibited P-gp-mediated BBR efflux. The results of in vitro metabolism experiments showed that the metabolic rate of BBR (Figure 4D) and the production of demethylberberine (Figure 4F) in the Nnps were significantly decreased compared with those in the BBR group, and the metabolic rate of BBR decreased by $29.27 \%$, whereas the production of demethylberberine decreased by $22.39 \%$. The elimination half-life of BBR was significantly prolonged from $149 \mathrm{~min}$ to $216 \mathrm{~min}$ (Figure 4E). In brief, these results indicated that the Nnps changed the absorption form of BBR, reduced its intestinal efflux, and improved its intestinal metabolic stability.

\section{Effects of the Nnps on the Pharmacokinetics of Oral BBR in Mice}

The Nnps had no significant effect on the pharmacokinetics of oral BBR in systemic circulation (Figure 5A, Table 2). However, compared with those in the BBRtreated group, the peak concentration $\left(\mathrm{C}_{\max }, 1182.3 \mathrm{vs}\right.$ $310.2 \mathrm{ng} / \mathrm{mL})$ and exposure level $\left(\mathrm{AUC}_{0-12 \mathrm{~h}}, 2842.8 \mathrm{vs}\right.$ $1447.0 \mathrm{ng} \cdot \mathrm{h} / \mathrm{mL}$ ) of BBR were significantly increased in the portal vein of mice in the Nnps-BBR-treated group (Figure 5B, Table 2), indicating that the Nnps promoted 

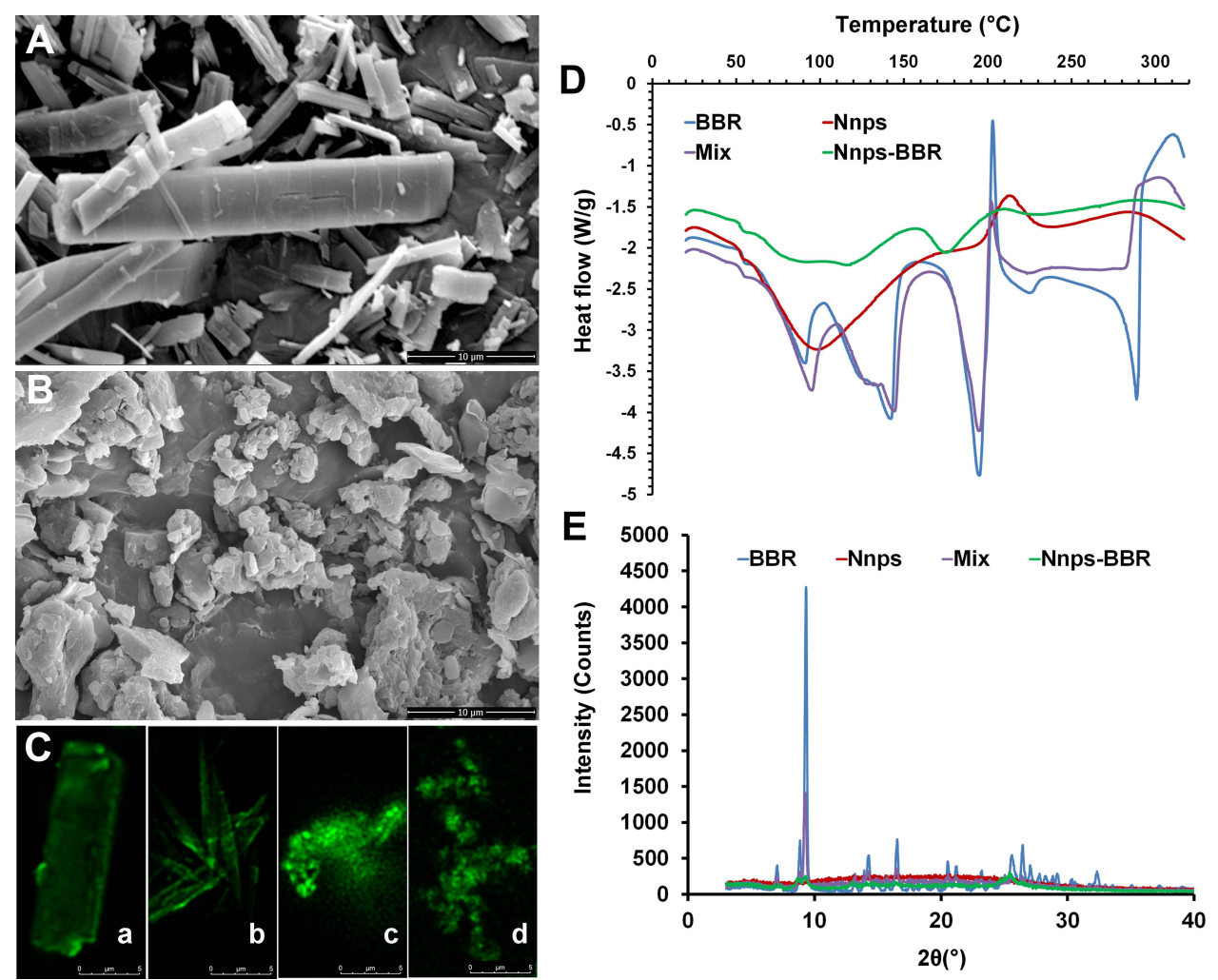

Figure 2 Natural nanoparticles (Nnps) changed the crystal form of berberine hydrochloride (BBR). Scanning electron microscopy images of BBR (A) and Nnps-BBR (B) (I0,000 ×); (C) Laser confocal fluorescence microscope observation (6000 ×) of BBR powder (a), BBR solution (b), Nnps-BBR powder (c), and Nnps-BBR solution (d); (D) Differential scanning calorimetry images of BBR, Nnps, the physical mixture of Nnps and BBR (Mix), and Nnps-BBR complex; (E) Powder X-ray diffraction images of BBR, Nnps, physical mixture of Nnps and BBR (Mix), and Nnps-BBR complex.
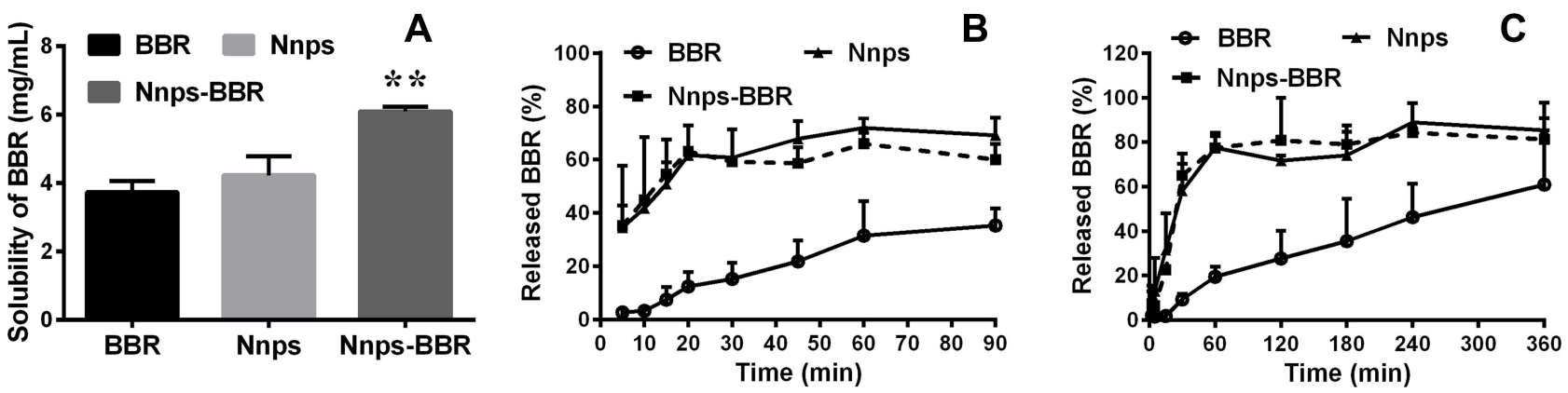

Figure 3 Effect of the natural nanoparticles (Nnps) on the solubility $(\mathbf{A})$ and dissolution profile of berberine hydrochloride (BBR) in simulated gastric $(\mathbf{B})$ or intestinal $(\mathbf{C})$ fluid (Mean $\pm \mathrm{SD}, \mathrm{n}=6$ ). ${ }^{* *} \mathrm{p}<0.0 \mathrm{I}$ vs BBR.

the intestinal absorption of BBR. Furthermore, the Nnps caused higher exposure level of BBR in mouse livers

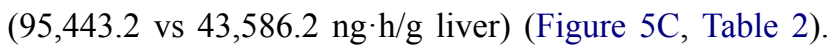
In addition, the pharmacokinetic parameters (Table 2), including $\mathrm{C}_{\max }$ and $\mathrm{AUC}_{0-12 \mathrm{~h}}$, in the Nnps-BBR group were similar to or slightly better than those in the Coptidis Rhizoma-treated group. In short, the Nnps improved the pharmacokinetics of oral BBR in mice.

\section{Discussion}

In this study, the Nnps isolated from Coptidis Rhizoma extract were mainly formed by denaturation of a protein (possibly glycosylated protein) having a molecular weight slightly smaller than $30 \mathrm{kDa}$. Because the protein was very pure, the Nnps with a relatively uniform size were quickly obtained by simple methods, including centrifugation, filtration, and dialysis, instead of further 

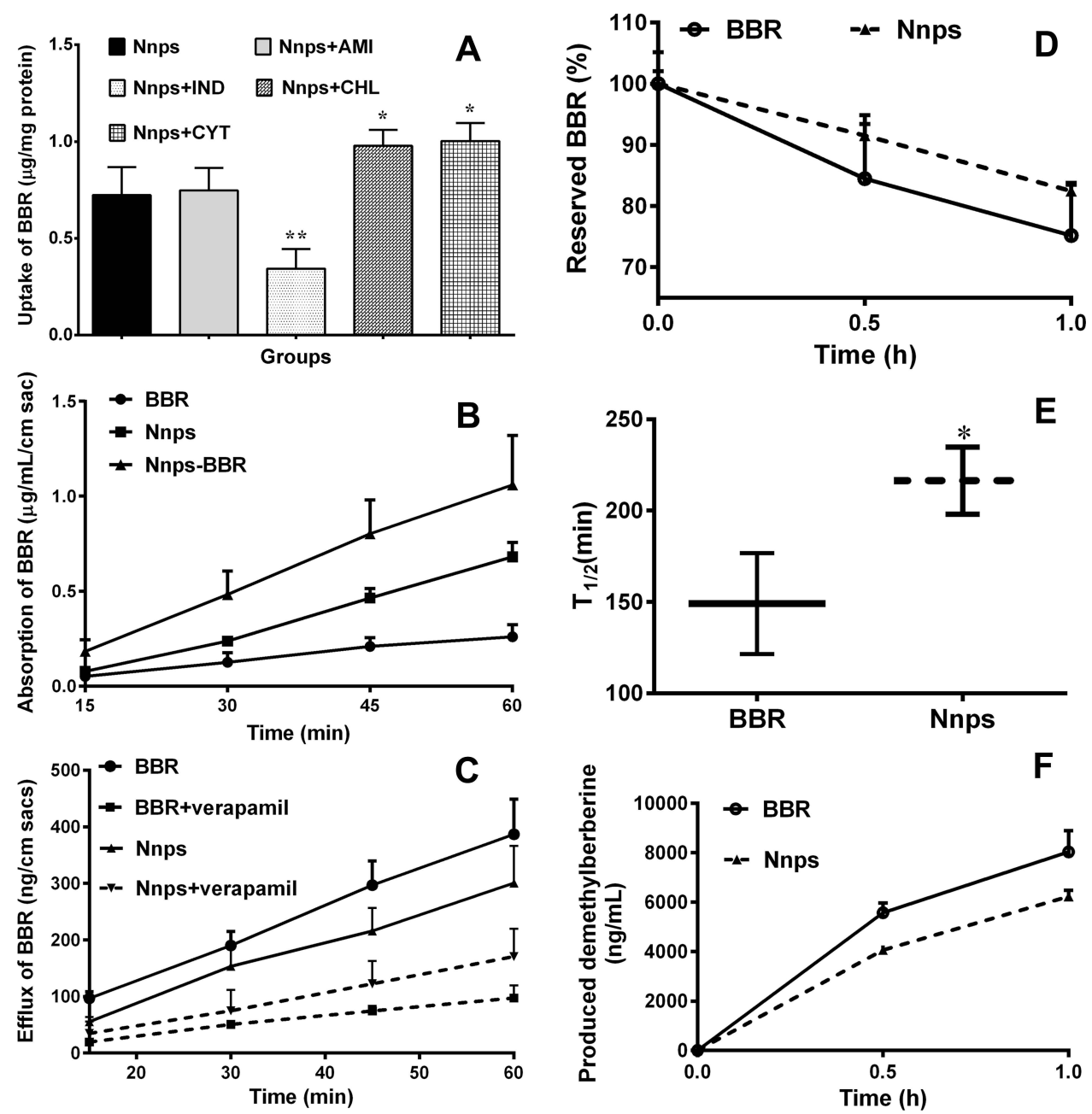

Figure 4 Effect of the natural nanoparticles (Nnps) on the intestinal absorption of berberine hydrochloride (BBR) (Mean \pm SD); (A) Effects of endocytosis inhibitors on the uptake of BBR $(10 \mu \mathrm{g} / \mathrm{mL})$ in Caco-2 cells $(\mathrm{n}=3) ;(B)$ Absorption of BBR $(10 \mathrm{mg} / \mathrm{mL})$ in the gut sacs $(\mathrm{n}=4)$; $(\mathbf{C})$ Efflux of BBR $(200 \mu \mathrm{g} / \mathrm{mL})$ in the gut sacs in the presence or absence of $100 \mu \mathrm{g} / \mathrm{mL}$ verapamil $(\mathrm{n}=4)$; (D) Elimination of BBR $(10 \mu \mathrm{g} / \mathrm{mL})$ in intestinal $\mathrm{S} 9(\mathrm{n}=3)$; $(\mathbf{E})$ Elimination half-life of BBR $(10 \mu \mathrm{g} / \mathrm{mL})$ in intestinal S9 $(\mathrm{n}=3)$; $(\mathbf{F})$ Production of demethylberberine after BBR $(10 \mu \mathrm{g} / \mathrm{mL})$ was incubated with intestinal $\mathrm{S} 9(\mathrm{n}=3)$. AMI, amiloride $(2.5 \mathrm{mM})$; BBR, berberine hydrochloride; CHL,

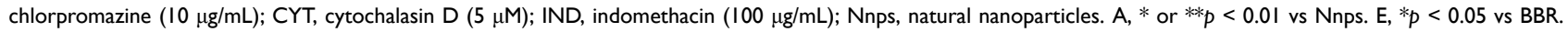

purification using size-exclusion high-performance liquid chromatography (SEC-HPLC). ${ }^{18}$ The size of the Nnps was less than $200 \mathrm{~nm}$, which helps prevent them from being swallowed by reticuloendothelial phagocytes

Table I Effect of Natural Nanoparticles (Nnps) on the Apparent Permeability $\left(P_{a p p}\right)$ and Efflux Rate (ER) of Berberine Hydrochloride (BBR) (Mean $\pm \mathrm{SD}, \mathrm{n}=3$ )

\begin{tabular}{|c|c|c|c|c|}
\hline Groups & $\begin{array}{c}\text { Incubation } \\
\text { Time (h) }\end{array}$ & $\begin{array}{l}P_{\text {app }}(\mathrm{AP}- \\
\mathrm{BL})\left(\times 10^{-6} \mathrm{~cm} / \mathrm{sec}\right)\end{array}$ & $\begin{array}{l}P_{a p P(B L-} \\
A P)\left(\times 10^{-6} \mathrm{~cm} / \mathrm{sec}\right)\end{array}$ & ERs \\
\hline BBR & $\begin{array}{l}2 \\
4\end{array}$ & $\begin{array}{l}0.71 \pm 0.03 \\
0.39 \pm 0.02\end{array}$ & $\begin{array}{l}18.2 \pm 1.9 \\
15.3 \pm 1.6\end{array}$ & $\begin{array}{l}25.8 \\
39.5\end{array}$ \\
\hline Nnps & $\begin{array}{l}2 \\
4\end{array}$ & $\begin{array}{l}0.64 \pm 0.09 \\
0.41 \pm 0.02\end{array}$ & $\begin{array}{l}10.7 \pm 0.6 * * \\
8.6 \pm 0.3 * *\end{array}$ & $\begin{array}{l}17.1^{* * *} \\
20.8^{* * *}\end{array}$ \\
\hline
\end{tabular}

Note: $* * p<0.01$ vs BBR. (macrophages). ${ }^{40}$ The Zeta potential of these nanoparticles indicated that their stability was insufficient, which led to the aggregation of nanoparticles observed in Figure $2 \mathrm{Cd}$. However, given that the Nnps would be taken immediately after preparation, extensive aggregation of the Nnps can be avoided. SEM observations, DSC, and PXRD experiments showed that the Nnps promoted the transformation of BBR into an amorphous form. Therefore, in Coptidis Rhizoma extract, the Nnps may act as a crystallization inhibitor of BBR. In other words, Coptidis Rhizoma extract could be regarded as a solid dispersion of BBR, where the Nnps act as carriers. In addition, the Nnps was able to form complex with BBR. According to the literature, ${ }^{41}$ hydrophobic interactions could be formed between the Nnps and 

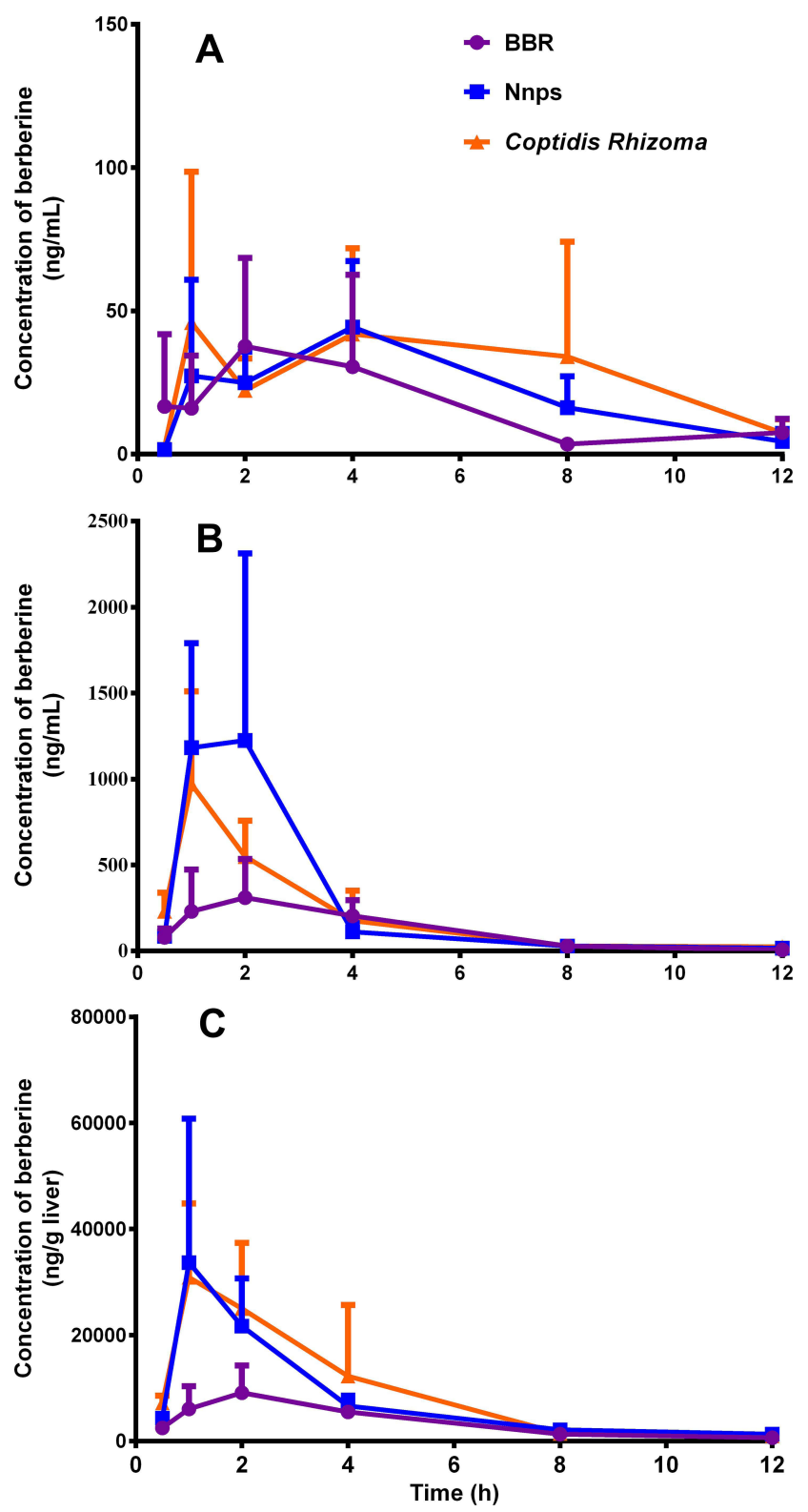

Figure 5 Concentration-time curves of berberine hydrochloride (BBR) in the systemic circulation (A), portal vein (B), and livers (C) of mice receiving $200 \mathrm{mg} /$ $\mathrm{kg}$ oral BBR, the complex of the natural nanoparticles (Nnps) and BBR (Nnps-BBR), and Coptidis Rhizoma extract, which all contained the corresponding dosage of BBR (Mean $\pm S D, n=6)$.

BBR. The Nnps-BBR complex was dispersed into nanoparticles in water, which once again showed that the Nnps had a significant and fundamental impact on the existing form of BBR.

Approximately $56 \%$ of $\mathrm{BBR}$ is directly discharged from the body after oral administration, which is related to the poor solubility of BBR. ${ }^{27}$ The common dosage of BBR in mice is $200 \mathrm{mg} / \mathrm{kg}^{27}$ Therefore, if BBR is administered at $0.2 \mathrm{~mL} / 10 \mathrm{~g}$ body weight, its concentration should be $10 \mathrm{mg} / \mathrm{mL}$. However, the solubility of BBR in this study was only approximately $3.7 \mathrm{mg} / \mathrm{mL}$, which meant that more than half of BBR was not dissolved. Through the formation of solid dispersions with BBR, the Nnps significantly improved the solubility and dissolution of BBR.

Nanoparticles are taken up by intestinal cells mainly via mechanisms including phagocytosis, macropinocytosis, caveolae-mediated endocytosis, and clathrin-mediated endocytosis, ${ }^{37}$ which are inhibited by cytochalasin $\mathrm{D},{ }^{31}$ amiloride, ${ }^{31}$ indomethacin, ${ }^{32}$ and chlorpromazine, ${ }^{32}$ respectively. Based on the experiments using Caco-2 cells, it was found that the Nnps carried BBR and promoted its uptake via an indomethacin-sensitive endocytosis mechanism. In other words, the Nnps changed the absorption form of BBR in the intestinal tract, that is, from passive diffusion ${ }^{26}$ to endocytosis. Usually, caveolae mediate the uptake of nanoparticles sized less than 100 $\mathrm{nm} .{ }^{42}$ However, some studies have shown that caveolae mediate the endocytosis of nanoparticles larger than 200 $\mathrm{nm}^{43}$ or even $500 \mathrm{~nm} .^{44}$ Importantly, caveolae-mediated endocytosis can bypass lysosomal degradation, ${ }^{37}$ suggesting that the Nnps can be transported into the circulation in the form of nanoparticles after being taken up by intestinal epithelial cells. Chlorpromazine and cytochalasin D promoted the uptake of BBR by the Nnps in this study, which might be related to their inhibitory effect on the efflux transporter P-gp. Given that chlorpromazine and cytochalasin D are substrates of P-gp, ${ }^{45,46}$ they can competitively inhibit the efflux of BBR.

According to literature, $43.5 \%$ of oral BBR is eliminated in the intestine. ${ }^{27}$ Cytochrome $\mathrm{P} 450$ enzymes (CYPs), especially CYP3A, play a major role in the Phase I metabolism of BBR. ${ }^{47}$ There are various CYPs in intestinal epithelial cells, especially CYP3A, which is highly expressed in the intestine. ${ }^{48}$ Our results showed that the Nnps significantly inhibited the phase I metabolism of BBR in the intestine, which was beneficial for increasing its intestinal absorption. This result was consistent with a previous report that curcumin loaded in polymer nanoparticles was not metabolized. ${ }^{49}$ In addition, there are many efflux transporters in intestinal epithelial cells, such as P-gp, which significantly reduces the uptake of their substrates. Moreover, there are synergistic effects between efflux transporters and metabolic enzymes, which jointly mediate the intestinal elimination of some drugs. ${ }^{50}$ For example, the phase I metabolic enzymes CYP3A4 and P-gp have many overlapping substrates. P-gp can affect drug metabolism in the intestine by decreasing trans-cell 
Table 2 Pharmacokinetic Parameters of Berberine Hydrochloride (BBR) in the Systemic Circulation, Portal Vein, and Livers of Mice Receiving $200 \mathrm{mg} / \mathrm{kg}$ Oral BBR, The Complex of the Nanoparticles and BBR (Nnps-BBR), and Coptidis Rhizoma Extract, Which All Contained the Corresponding Dosage of BBR (Mean \pm SD, $n=6$ )

\begin{tabular}{|c|c|c|c|c|}
\hline Samples & Parameters & BBR & Nnps-BBR & Coptidis Rhizome \\
\hline \multirow[t]{6}{*}{ Systemic circulation } & $\mathrm{T}_{\max }(\mathrm{h})$ & 2.0 & 4.0 & 1.0 \\
\hline & $\mathrm{C}_{\max }(\mathrm{ng} / \mathrm{mL})$ & 37.6 & 44.4 & 45.9 \\
\hline & $\mathrm{T}_{1 / 2}(\mathrm{~h})$ & 1.66 & 2.41 & 3.20 \\
\hline & $A \cup C_{0-12 h}(\mathrm{ng} \cdot \mathrm{h} / \mathrm{mL})$ & 199.3 & 268.9 & 351.2 \\
\hline & $\mathrm{AUC}_{0-\infty}(\mathrm{ng} \cdot \mathrm{h} / \mathrm{mL})$ & 201.1 & 285.1 & 393.9 \\
\hline & MRT (h) & 3.95 & 4.67 & 5.34 \\
\hline \multirow[t]{6}{*}{ Portal vein } & $\mathrm{T}_{1 / 2}(\mathrm{~h})$ & 1.60 & 2.89 & 1.43 \\
\hline & $\mathrm{T}_{\max }(\mathrm{h})$ & 2.0 & 1.0 & 1.0 \\
\hline & $\mathrm{C}_{\max }(\mathrm{ng} / \mathrm{mL})$ & 310.2 & 1182.3 & 970.5 \\
\hline & $A \cup C_{0-12 h}(\mathrm{ng} \cdot \mathrm{h} / \mathrm{mL})$ & 1447.0 & 2842.8 & 2480.9 \\
\hline & $\mathrm{AUC}_{0-\infty}(\mathrm{ng} \cdot \mathrm{h} / \mathrm{mL})$ & 1460.7 & 2902.8 & 2489.1 \\
\hline & MRT (h) & 3.22 & 2.21 & 2.47 \\
\hline \multirow[t]{6}{*}{ Livers } & $\mathrm{T}_{1 / 2}(\mathrm{~h})$ & 2.63 & 3.48 & 1.45 \\
\hline & $\mathrm{T}_{\max }(\mathrm{h})$ & 2.0 & 1.0 & 1.0 \\
\hline & $\mathrm{C}_{\max }$ (ng/g liver) & 9137.7 & $33,677.8$ & $30,878.4$ \\
\hline & $\mathrm{AUC}_{0-12 \mathrm{~h}}(\mathrm{ng} \cdot \mathrm{h} / \mathrm{g}$ liver $)$ & $43,586.2$ & $95,443.2$ & $112,942.0$ \\
\hline & $\mathrm{AUC}_{0-\infty}$ (ng $\mathrm{h} / \mathrm{g}$ liver) & $45,84 I .1$ & $101,503.0$ & I I3,426.I \\
\hline & MRT (h) & 3.64 & 2.89 & 2.85 \\
\hline
\end{tabular}

Abbreviations: AUC, the area under the concentration time curve; $C_{\max }$, peak concentration; MRT, mean retention time; $T_{1 / 2}$, elimination half-life; $T_{\text {max }}$, time to reach peak concentration.

transport and increasing the contact between the substrate and CYP3A4 at the tip of intestinal cells. ${ }^{51}$ Unfortunately, BBR is the substrate of both CYP3A4 and P-gp; thus, it is eliminated by the joint action of both in the intestinal absorption process. ${ }^{27}$ In this study, the Nnps significantly reduced the efflux of BBR in the gut sacs of mice. In addition, the Nnps significantly reduced the $P_{a p p}$ of BBR from the basal side to the lumen side and significantly reduced the ERs of BBR in MDCK-MDR1 cells. Because MDCK-MDR1 cells solely express P-gp, this result confirmed that the Nnps significantly inhibited P-gp-mediated BBR efflux. Similarly, after being loaded into the nanoparticles isolated from green tea infusions, doxorubicin was able to bypass the efflux function of P-gp. ${ }^{18,52}$

A pharmacokinetic study in mice showed that the Nnps significantly promoted the intestinal absorption of BBR, which was manifested by a significant increase in BBR exposure levels $\left(\mathrm{AUC}_{0-\mathrm{t}}\right.$ and $\left.\mathrm{C}_{\max }\right)$ in the portal vein. Thereafter, BBR distributed in the liver increased owing to increased intestinal absorption. However, the increase in BBR in systemic circulation was not as significant as that in the portal vein and liver. This result may be related to the active uptake of BBR by tissues, including liver tissue, which leads to the poor dose-exposure relationship of BBR in systemic circulation. ${ }^{28}$ The pharmacological effects of BBR in lowering blood sugar and lipids are the focus of the current research. ${ }^{53}$ The liver is the main tissue involved in glucose and lipid metabolism. ${ }^{54}$ Therefore, the increase in the exposure level of BBR in the liver suggests that the Nnps can enhance the pharmacological effects of BBR in reducing blood sugar and lipids. In addition, the exposure levels in the portal vein and livers of the mice in the Nnps-BBR-treated group were equivalent to those in the Coptidis Rhizoma extract-treated group, showing the high capability of the Nnps to improve the pharmacokinetic properties of BBR.

The interactions between the constituents of herbal extracts have always attracted much attention and are often used to explain the mechanism of synergy or toxicity reduction of TCMs. ${ }^{55}$ These interactions could occur at the levels of pharmacodynamics, pharmacokinetics, and chemistry. At the pharmacodynamic level, a multicomponent, multi-target point of view has been proposed. ${ }^{56}$ At the level of pharmacokinetics, interactions between the constituents based on drug-metabolizing enzymes and transporters are commonly reported. ${ }^{57}$ At the chemical level, it has been reported that some 
constituents, such as BBR and glycyrrhizic acid, ${ }^{58}$ can form complexes based on intermolecular interactions. In addition, BBR can form nanoparticles with baicalin and wogonin, which have a significant impact on their antibacterial effects. ${ }^{59}$ However, the abovementioned studies are limited for investigating the interactions between small-molecule constituents in herbal extracts. In this study, we found that a protein in Coptidis Rhizoma extract could interact with BBR, and the interaction mechanism was studied systematically from the chemical and pharmacokinetic levels for the first time. Given that Nnps formed by macromolecules are widespread in herbal extracts, we believe that this study will inspire more relevant research and contribute to revealing the mechanisms of intra-herb interactions.

\section{Conclusions}

In summary, the Nnps in Coptidis Rhizoma extract changed the existing form of BBR and promoted its transformation from crystal to amorphous form, thereby improving its solubility and dissolution. The Nnps also carried BBR and promoted its uptake by intestinal epithelial cells through caveolae-mediated endocytosis, and significantly reduced the intestinal metabolism and P-gp-mediated efflux of BBR. The mechanisms acted synergistically and ultimately promoted the intestinal absorption of BBR and increased its in vivo exposure levels. The study contributes to revealing the mechanisms of intra-herb interactions in Coptidis Rhizoma extract.

\section{Abbreviations}

$\mathrm{BBR}$, berberine hydrochloride; BCA, diquinolinic acid; Caco-2, human colonic adenocarcinoma cells; CYPs, cytochrome P450 enzymes; DMEM, Dulbecco's modified Eagle's medium; DMSO, dimethyl sulfoxide; DSC, differential scanning calorimetry; ER, efflux rate; ESI, electrospray ionization; HBSS, Hank's balanced salt solution; LCFM, laser confocal fluorescence microscope; LC-MS, liquid chromatography-mass spectrometry; LCMS/MS, liquid chromatography tandem mass spectrometry; MDCK-MDR1, Madin-Darby canine kidney cells stably expressing the transporter P- glycoprotein; $\mathrm{NADPH}$, reduced nicotinamide adenine dinucleotide phosphate; Nnps, natural nanoparticles; $P_{a p p}$, permeability; P-gp, p-glycoprotein; PXRD, powder X-ray diffraction; SEM, scanning electron microscope; TCMs, traditional Chinese medicines.

\section{Data Sharing Statement}

The datasets used and/or analyzed during the current study are available from the corresponding author Bing-Liang $\mathrm{Ma}$ on reasonable request.

\section{Ethics Approval and Informed Consent}

All animal experimental protocols were approved by the Institutional Animal Care and Use Committee of Shanghai University of Traditional Chinese Medicine (PZSHUTCM19011105). All experiments were performed in accordance with the Guidelines for Care and Use of Laboratory Animals of Shanghai University of Traditional Chinese Medicine.

\section{Funding}

This work was financially supported by Natural Science Foundation of Shanghai (17ZR1430400).

\section{Disclosure}

Jing Zhao and Qing Zhao share first authorship. The authors state no conflict of interest.

\section{References}

1. Ekor M. The growing use of herbal medicines: issues relating to adverse reactions and challenges in monitoring safety. Front Pharmacol. 2014;4:177.

2. Newman DJ, Cragg GM. Natural products as sources of new drugs from 1981 to 2014. J Nat Prod. 2016;79(3):629-661. doi:10.1021/acs. jnatprod.5b01055

3. Song M, Hang TJ, Zhang Z, Chen HY. Effects of the coexisting diterpenoid tanshinones on the pharmacokinetics of cryptotanshinone and tanshinone IIA in rat. Eur J Pharm Sci. 2007;32(4-5):247-253. doi:10.1016/j.ejps.2007.07.007

4. Liu YT, Hao HP, Xie HG, et al. Extensive intestinal first-pass elimination and predominant hepatic distribution of berberine explain its low plasma levels in rats. Drug Metab Dispos. 2010;38(10):1779-1784. doi: $10.1124 / \mathrm{dmd} .110 .033936$

5. Gu Y, Wang G, Pan G, et al. Transport and bioavailability studies of astragaloside IV, an active ingredient in Radix Astragali. Basic Clin Pharmacol Toxicol. 2004;95(6):295-298. doi:10.1111/j.17427843.2004.t01-1-pto950508.x

6. Xing J, Chen X, Sun Y, Luan Y, Zhong D. Interaction of baicalin and baicalein with antibiotics in the gastrointestinal tract. $J$ Pharm Pharmacol. 2005;57(6):743-750. doi:10.1211/0022357056244

7. Bangphumi K, Kittiviriyakul C, Towiwat P, Rojsitthisak P, Khemawoot P. Pharmacokinetics of curcumin diethyl disuccinate, a prodrug of curcumin, in Wistar rats. Eur J Drug Metab Pharmacokinet. 2016;41 (6):777-785. doi:10.1007/s13318-015-0308-Z

8. Zhao J, Su C, Yang CP, et al. Determination of ginsenosides Rb-1, $\mathrm{Rb}-2$, and $\mathrm{Rb}-3$ in rat plasma by a rapid and sensitive liquid chromatography tandem mass spectrometry method: application in a pharmacokinetic study. J Pharmaceut Biomed. 2012;64:6594-6597. doi:10.1016/j.jpba.2012.02.017 
9. Yamamura Y, Santa T, Kotaki H, et al. Administration-route dependency of absorption of glycyrrhizin in rats: intraperitoneal administration dramatically enhanced bioavailability. Biol Pharm Bull. 1995;18(2):337-341. doi:10.1248/bpb.18.337

10. Pei LX, Bao YW, Ma L, et al. A sensitive method for determination of platycodin $\mathrm{D}$ in rat plasma using liquid chromatography/tandem mass spectrometry and its application to a Pharmacokinetic Study. Planta Med. 2012;78(3):244-251. doi:10.1055/s-0031-1280372

11. Zhao Q, Luan X, Zheng M, et al. Synergistic mechanisms of constituents in herbal extracts during intestinal absorption: focus on natural occurring nanoparticles. Pharmaceutics. 2020;12(2):128. doi:10.3390/pharmaceutics12020128

12. Zhou -S-S, Xu J, Zhu H, et al. Gut microbiota-involved mechanisms in enhancing systemic exposure of ginsenosides by coexisting polysaccharides in ginseng decoction. Sci Rep Uk. 2016;6. doi:10.1038/ srep22474

13. Wang H-Y, Guo S-C, Peng Z-T, et al. Ophiopogon polysaccharide promotes the in vitro metabolism of ophiopogonins by human gut microbiota. Molecules. 2019;24(16). doi:10.3390/molecules2 4162886

14. Zhuang Y, Yan J, Zhu W, et al. Can the aggregation be a new approach for understanding the mechanism of traditional Chinese medicine? J Ethnopharmacol. 2008;117(2):378-384. doi:10.1016/j. jep.2008.02.017

15. Zhou J, Liu J, Lin D, et al. Boiling-induced nanoparticles and their constitutive proteins from isatis indigotica fort. root decoction: purification and identification. J Tradit Complement Med. 2017;7 (2):178-187. doi:10.1016/j.jtcme.2016.08.007

16. Hasson TH, Takaoka A, de la Rica R, et al. Immunostimulatory lipid nanoparticles from herbal medicine. Chem Biol Drug Des. 2014;83 (4):493-497. doi:10.1111/cbdd.12250

17. Zhuang $\mathrm{X}$, Deng $\mathrm{ZB}, \mathrm{Mu} \mathrm{J}$, et al. Ginger-derived nanoparticles protect against alcohol-induced liver damage. J Extracell Vesicles. 2015:428713. doi:10.3402/jev.v4.28713

18. Yi S, Wang Y, Huang Y, et al. Tea nanoparticles for immunostimulation and chemo-drug delivery in cancer treatment. $J$ Biomed Nanotechnol. 2014;10(6):1016-1029. doi:10.1166/jbn.2014.1782

19. Huang Y, Wang YJ, Wang Y, et al. Exploring naturally occurring ivy nanoparticles as an alternative biomaterial. Acta Biomater. 2015:25268-25283. doi:10.1016/j.actbio.2015.07.035

20. Ma BL, Yin C, Zhang BK, et al. Naturally occurring proteinaceous nanoparticles in Coptidis Rhizoma extract act as concentration-dependent carriers that facilitate berberine absorption. Sci Rep. 2016:620110. doi:10.1038/srep20110

21. Zhou J, Gao G, Chu Q, et al. Chromatographic isolation of nanoparticles from Ma-Xing-Shi-Gan-Tang decoction and their characterization. $J$ Ethnopharmacol. 2014;151(3):1116-1123. doi:10.1016/j.jep.2013.12.029

22. Ke LJ, Gao GZ, Shen Y, Zhou JW, Rao PF. Encapsulation of aconitine in self-assembled licorice protein nanoparticles reduces the toxicity in vivo. Nanoscale Res Lett. 2015;10(1):449. doi:10.1186/ s11671-015-1155-1

23. Zhang MZ, Xiao B, Wang H, et al. Edible ginger-derived nano-lipids loaded with doxorubicin as a novel drug-delivery approach for colon cancer therapy. Mol Ther. 2016;24(10):1783-1796. doi:10.1038/ mt.2016.159

24. Wang G, Yang C, Zhang K, Hu J, Pang W. Molecular clusters size of Puerariae thomsonii radix aqueous decoction and relevance to oral absorption. Molecules. 2015;20(7):12376-12388. doi:10.3390/ molecules200712376

25. Kumar A, Ekavali CK. Current knowledge and pharmacological profile of berberine: an update. Eur J Pharmacol. 2015:761288-761297. doi:10.1016/j.ejphar.2015.05.068
26. Ma B-L, Ma Y-M. Pharmacokinetic properties, potential herb-drug interactions and acute toxicity of oral Rhizoma coptidis alkaloids. Expert Opin Drug Metab Toxicol. 2013;9(1):51-61. doi:10.1517/ 17425255.2012.722995

27. Liu CS, Zheng YR, Zhang YF, Long XY. Research progress on berberine with a special focus on its oral bioavailability. Fitoterapia. 2016;109274-109282. doi:10.1016/j.fitote.2016.02.001

28. Li Q, Yang Y, Zhou T, et al. A compositive strategy to study the pharmacokinetics of TCMs: taking coptidis rhizoma, and coptidis rhizoma-glycyrrhizae radix et rhizoma as examples. Molecules. 2018;23(8):E2042. doi:10.3390/molecules23082042

29. Ma BL, Yang Y, Dai Y, et al. Polyethylene glycol 400 (PEG400) affects the systemic exposure of oral drugs based on multiple mechanisms: taking berberine as an example. RSC Adv. 2017;7 (5):2435-2442. doi:10.1039/c6ra26284h

30. Ma BL, Yao MK, Zhong J, et al. Increased systemic exposure to rhizoma coptidis alkaloids in lipopolysaccharide-pretreated rats attributable to enhanced intestinal absorption. Drug Metab Dispos. 2012;40(2):381-388. doi:10.1124/dmd.111.041152

31. Wadia JS, Stan RV, Dowdy SF. Transducible TAT-HA fusogenic peptide enhances escape of TAT-fusion proteins after lipid raft macropinocytosis. Nat Med. 2004;10(3):310-315. doi:10.1038/ nm996

32. Mahmood A, Prufert F, Efiana NA, et al. Cell-penetrating self-nanoemulsifying drug delivery systems (SNEDDS) for oral gene delivery. Expert Opin Drug Deliv. 2016;13(11):1503-1512. doi:10.1080/17425247.2016.1213236

33. Felz S, Vermeulen P, van Loosdrecht MCM, Lin YM. Chemical characterization methods for the analysis of structural extracellular polymeric substances (EPS). Water Res. 2019;157201-157208. doi:10.1016/j.watres.2019.03.068

34. Uzasci S, Erim FB. Enhancement of native fluorescence intensity of berberine by (2-hydroxypropyl)-beta-cyclodextrin in capillary electrophoresis coupled by laser-induced fluorescence detection: application to quality control of medicinal plants. $J$ Chromatogr A. 2014;1338184-1338187. doi:10.1016/j.chroma.2014.02.068

35. Tong HHY, Chow ASF, Chan HM, et al. Process-induced phase transformation of berberine chloride hydrates. J Pharm Sci. 2010;99 (4):1942-1954. doi:10.1002/jps.21983

36. Williams HD, Trevaskis NL, Charman SA, et al. Strategies to address low drug solubility in discovery and development. Pharmacol Rev. 2013;65(1):315-499. doi:10.1124/pr.112.005660

37. Sahay G, Alakhova DY, Kabanov AV. Endocytosis of nanomedicines. $J$ Control Release. 2010;145(3):182-195. doi:10.1016/j. jconrel.2010.01.036

38. Lemma GL, Wang Z, Hamman MA, et al. The effect of short- and long-term administration of verapamil on the disposition of cytochrome P450 3A and P-glycoprotein substrates. Clin Pharmacol Ther. 2006;79(3):218-230. doi:10.1016/j.clpt.2005.11.001

39. Giacomini KM, Huang SM, Tweedie DJ, et al. Membrane transporters in drug development. Nat Rev Drug Discov. 2010;9(3):215-236. doi: $10.1038 / \mathrm{nrd} 3028 \mathrm{nrd} 3028$

40. Choi JS, Cao J, Naeem M, et al. Size-controlled biodegradable nanoparticles: preparation and size-dependent cellular uptake and tumor cell growth inhibition. Colloids Surf B Biointerfaces. 2014:122545-122551. doi:10.1016/j.colsurfb.2014.07.030

41. Tang CH. Strategies to utilize naturally occurring protein architectures as nanovehicles for hydrophobic nutraceuticals. Food Hydrocoll. 2021;112:106344. doi:10.1016/j.foodhyd.2020.106344

42. Iversen TG, Skotland T, Sandvig K. Endocytosis and intracellular transport of nanoparticles: present knowledge and need for future studies. Nano Today. 2011;6(2):176-185. doi:10.1016/j. nantod.2011.02.003 
43. Rejman J, Conese M, Hoekstra D. Gene transfer by means of lipoand polyplexes: role of clathrin and caveolae-mediated endocytosis. J Liposome Res. 2006;16(3):237-247. doi:10.1080/089821006 00848819

44. Rejman J, Oberle V, Zuhorn IS, Hoekstra D. Size-dependent internalization of particles via the pathways of clathrin- and caveolae-mediated endocytosis. Biochem J. 2004;377(Pt 1):159-169. doi:10.1042/BJ20031253

45. Brown D, Goosen TC, Chetty M, Hamman JH. Effect of oral contraceptives on the transport of chlorpromazine across the CACO-2 intestinal epithelial cell line. Eur J Pharm Biopharm. 2003;56 (2):159-165. doi:10.1016/s0939-6411(03)00110-3

46. Trendowski M, Christen TD, Acquafondata C, Fondy TP. Effects of cytochalasin congeners, microtubule-directed agents, and doxorubicin alone or in combination against human ovarian carcinoma cell lines in vitro. BMC Cancer. 2015;15632. doi:10.1186/s12885-015-1619-9

47. Liu Y, Hao H, Xie H, et al. Oxidative demethylenation and subsequent glucuronidation are the major metabolic pathways of berberine in rats. J Pharm Sci. 2009;98(11):4391-4401. doi:10.1002/jps.21721

48. Paine MF, Hart HL, Ludington SS, et al. The human intestinal cytochrome P450 "pie”. Drug Metab Dispos. 2006;34(5):880-886. doi: $10.1124 /$ dmd.105.008672

49. Zou P, Helson L, Maitra A, Stern ST, McNeil SE. Polymeric curcumin nanoparticle pharmacokinetics and metabolism in bile duct cannulated rats. Mol Pharm. 2013;10(5):1977-1987. doi:10.1021/ mp4000019

50. Yasuda K, Lan LB, Sanglard D, et al. Interaction of cytochrome P450 3A inhibitors with P-glycoprotein. J Pharmacol Exp Ther. 2002;303 (1):323-332. doi:10.1124/jpet.102.037549

51. Cummins LC, Jacobsen W, Benet LZ. Unmasking the dynamic interplay between intestinal P-glycoprotein and CYP3A4. J Pharmacol Exp Ther. 2002;300(3):1036-1045. doi:10.1124/jpet.300.3.1036
52. Wang YJ, Huang YJ, Anreddy N, et al. Tea nanoparticle, a safe and biocompatible nanocarrier, greatly potentiates the anticancer activity of doxorubicin. Oncotarget. 2016;7(5):5877-5891. doi:10.18632/ oncotarget.6711

53. Lan J, Zhao Y, Dong F, et al. Meta-analysis of the effect and safety of berberine in the treatment of type 2 diabetes mellitus, hyperlipemia and hypertension. $J$ Ethnopharmacol. 2015:16169-16181. doi:10.1016/j.jep.2014.09.049

54. Rui L. Energy metabolism in the liver. Compr Physiol. 2014;4 (1):177-197. doi:10.1002/cphy.c130024

55. Caesar LK, Cech NB. Synergy and antagonism in natural product extracts: when $1+1$ does not equal 2. Nat Prod Rep. 2019;36 (6):869-888. doi:10.1039/c9np00011a

56. Ji HF, Li XJ, Zhang HY. Natural products and drug discovery. Can thousands of years of ancient medical knowledge lead us to new and powerful drug combinations in the fight against cancer and dementia? EMBO Rep. 2009;10(3):194-200. doi:10.1038/embor.2009.12

57. Yang Y, Zhang Z, Li S, et al. Synergy effects of herb extracts: pharmacokinetics and pharmacodynamic basis. Fitoterapia. 2014:92133-92147. doi:10.1016/j.fitote.2013.10.010

58. Li Z, Liu T, Liao J, et al. Deciphering chemical interactions between Glycyrrhizae Radix and Coptidis Rhizoma by liquid chromatography with transformed multiple reaction monitoring mass spectrometry. J Sep Sci. 2017;40(6):1254-1265. doi:10.1002/jssc.201601054

59. Li T, Wang P, Guo W, et al. Natural berberine-based Chinese herb medicine assembled nanostructures with modified antibacterial application. ACS Nano. 2019;13(6):6770-6781. doi:10.1021/ acsnano.9b01346
International Journal of Nanomedicine

\section{Publish your work in this journal}

The International Journal of Nanomedicine is an international, peerreviewed journal focusing on the application of nanotechnology in diagnostics, therapeutics, and drug delivery systems throughout the biomedical field. This journal is indexed on PubMed Central, MedLine, CAS, SciSearch ${ }^{\mathbb{R}}$, Current Contents ${ }^{\mathbb{R}} /$ Clinical Medicine, $^{2}$

\section{Dovepress}

Journal Citation Reports/Science Edition, EMBase, Scopus and the Elsevier Bibliographic databases. The manuscript management system is completely online and includes a very quick and fair peer-review system, which is all easy to use. Visit http://www.dovepress.com/ testimonials.php to read real quotes from published authors. 